Research Paper

\title{
Current Situation of Treatment and Follow-up Re-examination of Children with Epilepsy at Vietnam National Children's Hospital
}

\author{
Tran Thi Huyen ${ }^{1, *}$, Cao Vu Hung ${ }^{2}$, Tran Van $\mathrm{Hoc}^{2}$, Nguyen Danh Ngon ${ }^{2}$ \\ ${ }^{I}$ Thai Bình Children's Hospital, No 2 Ton That Tung, \\ Tran Lam, Thai Binh City, Thai Binh, Vietnam \\ ${ }^{2}$ Vietnam National Children's Hospital, 18/879 La Thanh, Dong Da, Hanoi, Vietnam
}

Received 17 August 2020

Revised 24 August 2020; Accepted 03 September 2020

\begin{abstract}
Purpose: To assess treatment compliance and follow-up appointment of children with epilepsy at Vietnam National Children's Hospital in 2019.

Methods: A cross-sectional descriptive study was conducted on pediatric patients and primary caregivers came for examination and treatment at the Neurology Department, Vietnam National Children's Hospital from January 2019 to December 2019.

Results: Mean age was $74.3 \pm 45.1$ (month age). The most common age group was the 2-6 year old group $(40.5 \%)$, the lower rate was the 6-12 year old group (30.0\%), and rest groups was the low rate. The male: female ratio is 1.43:1. Most of the main caregivers are parents $(92.5 \%)$. Average treatment time was $20.4 \pm 15.7$ months, the rate of good adherence to treatment $43.5 \%, 31.5 \%$ of children had moderated adhering to treatment and $25.0 \%$ had poor adhering to treatment. Within 6 months, $40.5 \%$ of children re-examined on time. The reasons for not complying with on-time re-examination were mainly due to the caregiver's busy work or the child was busy at school (37.8\%) and the distance from home to hospital (26.1\%).

Conclusions: The percentage of patients who complied with treatment and re-examination is not high. Factors that were statistically significant for children's non-compliance are health insurance level, age of onset, duration of treatment, and frequency of attacks following treatment.
\end{abstract}

Keywords: Treatment compliance, re-examination, epilepsy, children

\footnotetext{
* Corresponding author.

E-mail address: tthuyenytb@gmail.com

https://doi.org/10.25073/ jprp.v4i5.232
} 


\title{
Thực trạng tuân thủ điều trị của trẻ động kinh tại Bệnh viện Nhi Trung ương
}

\author{
Trần Thị Huyền ${ }^{1, *}$, Cao Vũ Hùng ${ }^{2}$, Trần Văn Học ${ }^{2}$, Nguyễn Danh Ngôn ${ }^{2}$ \\ ${ }^{1}$ Bệnh viện Nhi Thái Bình, Số 02 phố Tôn Thất Tùng, Trần Lãm, \\ Thành phố Thái Bình, Thái Bình, Việt Nam \\ ${ }^{2}$ Bệnh viện Nhi Trung ưong, 18/879 La Thành, Đống Đa, Hà Nội, Việt Nam
}

Nhận ngày 17 tháng 8 năm 2020

Chỉnh sửa ngày 24 tháng 8 năm 2020; Chấp nhận đăng ngày 3 tháng 9 năm 2020

\section{Tóm tắt}

Mục tiêu: Đánh giá tuân thủ điều trị và tái khám theo hẹn của trẻ động kinh tại Bệnh viện Nhi Trung ương năm 2019.

Đối tượng: Thực hiện 01 nghiên cứu cắt ngang trên bệnh nhi và người chăm sóc chính đến khám và điều trị tại Khoa thần kinh, Bệnh viện Nhi Trung ương từ tháng 01/2019 đến tháng 12/2019.

Kết quả: Tuổi trung bình là 74,3 \pm 45,1 (tháng tuổi). Nhóm tuổi thường gặp nhất là nhóm 2-6 tuổi $(40,5 \%)$, thấp hơn là nhóm 6-12 tuổi $(30,0 \%)$, các nhóm còn lại có tỷ lệ thấp. Tỷ lệ nam: nữ là 1,43:1. Hầu hết người chăm sóc chính là cha mẹ $(92,5 \%)$. Thời gian điều trị trung bình là 20,4 $\pm 15,7$ tháng, tỷ lệ trẻ tuân thủ điều trị tốt 43,5\%,31,5\% trẻ tuân thủ điều trị trung bình và $25,0 \%$ tuân thủ điều trị kém, trong vòng 6 tháng có $40,5 \%$ trẻ tái khám đúng hẹn. Lý do không tuân thủ tái khám đúng hẹn chủ yếu do người nuôi dưỡng bận việc hoặc trẻ bận học $(37,8 \%)$ và khoảng cách từ nhà tới bệnh viện xa $(26,1 \%)$

Kết luận: Tỷ lệ bệnh nhân tuân thủ điều trị và tái khám không cao. Các yếu tố liên quan có ý nghĩa thống kê với việc không tuân thủ điều trị thuốc ở trẻ em đó là: mức độ bảo hiểm $\mathrm{y}$ tế, tuổi khởi phát cơn, thời gian điều trị bệnh và tần suất cơn sau điều trị bệnh.

Tù khóa: Tuân thủ điều trị, tái khám, động kinh, trẻ em.

\section{1. Đặt vấn đề}

Động kinh là bệnh lý thần kinh trung ương thườn gặp, chiểm khoảng $0,5 \%$ dân số toàn cầu, trong đó $75 \%$ tại các nước đang phát triển [1]. Bệnh động kinh có thể xảy ra ở mọi lứa tuổi tuy nhiên tỷ lệ ở trẻ em cao hơn người lớn. Các nghiên cứ của tác giả trong và ngoài nước cho thấy có thể điều trị thành công với thuốc chống động kinh

*Tác giả liên hệ.

Địa chi email: tthuyenytb@gmail.com

https://doi.org/10.25073/ jprp.v4i5.232
[2-4]. Những trường hợp thất bại thường là bởi sự kém tuân thủ điều trị của người bệnh [5]. Tuy nhiên, khác với người lớn, trẻ em thường có sự tuân thủ điều trị kém hơn. Hiện tại Việt Nam chưa có nhiều nghiên cứu về vấn đề này, đặc biệt là ở trẻ em. Chính bởi vậy chúng tôi tiến hành nghiên cứu nhằm mục tiêu: "Đánh giá tuân thủ điều trị và tái khám theo hẹn của trẻ động kinh tại Bệnh viện Nhi Trung ương năm 2019”.

\section{2. Đối tượng và phương pháp nghiên cứu}


2.1. Đối turợng, địa điểm và thời gian nghiên cúu

Bệnh nhi và người chăm sóc chính đến khám, điều trị tại khoa Thần kinh, Bệnh viện Nhi Trung ương từ tháng $01 / 2019$ đến tháng 12/2019.

\subsection{Tiêu chuẩn lựa chọn}

- Trẻ được bác sĩ chuyên khoa chẩn đoán động kinh bằng lâm sàng và/hoặc điện não đồ.

- Trẻ đang điều trị ít nhất một thuốc chống động kinh tối thiểu 6 tháng.

- Trẻ có sổ khám bệnh với đầy đủ thông tin về chẩn đoán, đơn thuốc và ngày tái khám trong đó có ít nhất 2 đơn kèm ngày hẹn tái khám trong 6 tháng gần nhất với thời điểm lấy số liệu.

- Người chăm sóc chính của bệnh nhi hợp tác, đồng ý tham gia nghiên cứu.

\subsubsection{Tiêu chuẩn loại trừ}

- Trẻ không đủ tiêu chuẩn chấn đoán.

- Trẻ chưa được điều trị thuốc chống động kinh.

- Trẻ được chẩn đoán và điều trị thuốc chống động kinh tại cơ sở y tế khác.

- Sổ khám bệnh không đầy đủ.

- Người chăm sóc chính của bệnh nhi không đồng ý tham gia nghiên cứu.

\subsection{Phuoong pháp nghiên cứu}

\subsubsection{Thiết kế nghiên cứu}

Mô tả cắt ngang.

2.2.2. Cỡ mẫu và chọn mẫu nghiên cứu
Tính theo công thức cỡ mẫu ước lượng một tỷ lệ:

$$
n=Z_{(1-\alpha / 2)}^{2} \frac{p \cdot(1-p)}{d^{2}}
$$

Cỡ mẫu nhóm trẻ cần khảo sát: $\mathrm{n}$ là cỡ mẫu tối thiểu cần điều tra, $\alpha$ là ý nghĩa thống kê, ở mức $\alpha=0,05$ giá trị $\mathrm{Z}$ tương ứng là 1,96. $\mathrm{p}=0,418$ theo tỷ lệ tuân thủ điều trị tốt là $41,8 \%$ trong nghiên cứu của Trần Diệp Tuấn [1]. $\mathrm{d}$ là sai số mong đợi, lấy $\mathrm{d}=0,07$. Thay vào công thức tính được $\mathrm{n}=191$ trẻ.

Chúng tôi lấy tròn cỡ mẫu là 200 trẻ và bà mẹ.

\subsubsection{Nội dung và phương pháp thu thập}

Để đánh giá mức độ tuân thủ điều trị, nghiên cứu sử dụng bảng "The Morisky 8 item medication adherence scale". Bảng đánh giá này được dịch sang tiếng Việt, thay đổi cấu trúc cho phù hợp với người hỏi là người chăm sóc chính của trẻ. Tuân thủ điều trị kém khi tổng điểm $<6$, trung bình khi 6-7 điểm và tốt khi đạt 8 điểm.

Để đo lường tái khám theo hẹ, chúng tôi dựa vào các lần tái khám gần nhất trong vòng 6 tháng trước thời điểm nghiên cứu. Theo WHO, khám đúng hẹn là khi đến khám đúng ngày được hẹn trước hoặc trước và sau ngày hẹn 1 ngày. Những trường hợp trễ hơn được xem là tái khám trễ.

Bảng 1. Thang điểm đánh giá Morisky

\begin{tabular}{|c|c|}
\hline Nội dung & Đánh giá \\
\hline $\begin{array}{c}\text { Bạn có thỉnh thoảng quên } \\
\text { cho trẻ uống thuốc không? }\end{array}$ & $\begin{array}{c}\text { "Không" }=1 ; \\
\text { "Có" }=0\end{array}$ \\
\hline $\begin{array}{c}\text { Trong 2 tuần qua, bạn có } \\
\text { quên cho trẻ uống thuốc } \\
\text { ngày nào không? }\end{array}$ & $\begin{array}{c}\text { "Không" }=1 ; \\
\text { "Có" }=0\end{array}$ \\
\hline $\begin{array}{c}\text { Bạn có bao giờ tự ngưng } \\
\text { thuốc mà không hỏi ý kiển }\end{array}$ & $\begin{array}{c}\text { "Không" }=1 ; \\
\text { "Có" }=0\end{array}$ \\
\hline
\end{tabular}




\begin{tabular}{|c|c|}
\hline $\begin{array}{c}\text { bác sĩ khi cảm thấy trẻ co } \\
\text { giật nhiều hơn khi uống } \\
\text { thuốc không? }\end{array}$ & \\
\hline $\begin{array}{l}\text { Khi bạn và trẻ đi xa nhà } \\
\text { vài ngày, bạn có quên } \\
\text { mang thuốc theo không? }\end{array}$ & $\begin{array}{c}\text { "Không" = } 1 ; \\
\text { "Có" }=0\end{array}$ \\
\hline $\begin{array}{l}\text { Ngày hôm qua, bạn có cho } \\
\text { trẻ uống đầy đủ thuốc như } \\
\text { trong đơn không? }\end{array}$ & $\begin{array}{c}\text { "Không" = 1; } \\
\text { "Có" }=0\end{array}$ \\
\hline $\begin{array}{c}\text { Khi bạn thấy trẻ hết co } \\
\text { giật, bạn có ngưng cho trẻ } \\
\text { uống thuốc hay không? }\end{array}$ & $\begin{array}{c}\text { "Không" = } 1 ; \\
\text { "Có" }=0\end{array}$ \\
\hline $\begin{array}{c}\text { Bạn có thấy việc cho trẻ } \\
\text { uống thuốc mỗi ngày } \\
\text { khiến bạn cảm thấy rắc rối } \\
\text { phức tạp không? }\end{array}$ & $\begin{array}{l}\text { "Không" = 1; } \\
\text { "Có" }=0\end{array}$ \\
\hline $\begin{array}{c}\text { Việc không nhớ cho trẻ } \\
\text { uống thuốc xảy ra thường } \\
\text { xuyên như thế nào? }\end{array}$ & $\begin{array}{l}\text { "Không bao giờ } \\
\text { quên" = } 4 \\
\text { "Lâu lâu mới } \\
\text { quên" = } 3 \\
\text { "Thỉnh thoảng" } \\
=2 \\
\text { "Thường } \\
\text { xuyên" = } 1 \\
\text { "Ngày nào cũng } \\
\text { quên" = } 0 \\
\text { Lấy điểm số } \\
\text { chia cho } 4 .\end{array}$ \\
\hline
\end{tabular}

\subsubsection{Xử lý số liệu}

Số liệu được nhập bằng phần mềm Epi data 3.1 và xử lý bằng phần mềm thống kê SPSS 20.0.

\section{Kết quả nghiên cứu và bàn luận}

Việc tuân thủ điều trị khó có thể đo lường một cách chính xác. Có nhiều phương pháp đánh giá tuân thủ điều trị: trực tiếp, gián tiếp với nhiều ưu và nhược điểm riêng. Trong đó đánh giá qua báo cáo của bệnh nhân và người chăm sóc là thông dụng và dễ sử dụng nhất. Phương pháp này không xâm lấn, nhanh, rẻ tiền, có thể triển khai với cỡ mẫu lớn. Đây chính là lý do chúng tôi lựa chọn thang đo Morisky để đánh giá mức độ tuân thủ điều trị trẻ động kinh.

\section{1. Đặc điểm mỗi nghiên cứu}

Nghiên cứu của chúng tôi có 200 bệnh nhi, tuổi trung bình là 74,3 $\pm 45,1$ (tháng tuổi). Nhóm tuổi thường gặp nhất là nhóm 2-6 tuổi (40,5\%), thấp hơn là nhóm 6-12 tuổi (30,0\%), các nhóm còn lại có tỷ lệ thấp. Tỷ lệ nam: nữ là $1,43: 1$. Hầu hết người chăm sóc chính là cha mẹ (92,5\%). Chỉ có 3,5\% đang sống ly thân hoặc góa. Có 31,0\% tốt nghiệp trung học phổ thông trở lên.

Có $16,0 \%$ trẻ có tiền sử gia đình có người mắc động kinh hoặc sốt cao co giật. Phần lớn trẻ động kinh không có các bệnh lý kèm theo (78,0\%). Hội chứng động kinh cục bộ chiếm tỷ lệ cao nhất với 55,0\%, ít hơn là hội chứng động kinh toàn thể với $42,5 \%$ và thấp nhất là hội chứng động kinh đặc biệt (2,5\%). Trung bình khởi phát cơn động kinh là 39,3 $\pm 31,2$ tháng tuổi. Đa số khởi phát trước 1 tuổi.

Thời gian điều trị trung bình là $20,4 \pm$ 15,7 tháng, trong đó $40,0 \%$ dưới 1 năm. Thuốc chống động kinh được sử dụng nhiều nhất là sodium valproate $(91,5 \%)$. Đa số trẻ chỉ uống 1 loại thuốc $(72,5 \%)$ và uống 2 lần/ngày $(83,0 \%)$. Phần lớn trẻ uống không có tác dụng phụ $(75,5 \%)$.

\subsection{Tỷ lệ tuân thủ điều trị}

Bảng 2. Tuân thủ điều trị của trẻ động kinh

\begin{tabular}{|c|c|c|}
\hline Tuân thủ điều trị & Số lượng & Tỷ lệ \% \\
\hline Tuân thủ tốt & 87 & 43,5 \\
\hline Tuân thủ trung bình & 63 & 31,5 \\
\hline Tuân thủ kém & 50 & 25,0 \\
\hline
\end{tabular}

Tính theo thang đo Morisky, có 43,5\% trẻ tuân thủ điều trị tốt, $31,5 \%$ trẻ tuân thủ điều 
trị trung bình và $25,0 \%$ tuân thủ điều trị kém. Các nghiên cứu về tuân thủ điều trị dùng thuốc ở trẻ em ít hơn người lớn, đặc biệt là về động kinh. Nghiên cứu tổng hợp của Shope (1981) về tuân thủ thuốc ở trẻ em từ 1960 đến 1980 có 16 nghiên cứu nhưng chỉ có 5 nghiên cứu liên quan tới động kinh. Trong các nghiên cứu này, tỷ lệ tuân thủ dao động từ $25 \%-75 \%$ [5]. Nghiên cứu của Deogratias $\mathrm{M}$ Katabalo có phương pháp gần giống với chúng tôi cho thấy tỷ lệ tuân thủ tốt là $36,9 \%$, trung bình là $39,8 \%$ và kém là $23,3 \%$ [6]. Trần Diệp Tuấn nghiên cứu sự tuân thủ điều trị của các trẻ khu vực miền Nam cũng cho ra kết quả tương đồng với nghiên cứu của chúng tôi [1].

Trong nghiên cứu này, lý do không tuân thủ điều trị chủ yếu do người nuôi dưỡng trẻ bận. Lý do không tuân thủ điều trị do người nuôi trẻ bận $(37,2 \%)$, tự nhiên quên $(24,8 \%)$, sợ tác dụng phụ $(8,0 \%)$, quên khi đi xa $(5,3 \%)$, nghĩ trẻ đã khỏi bệnh $(2,6 \%)$, không muốn người khác biết trẻ bị bệnh $(2,6 \%)$ và không mua được thuốc $(1,8 \%)$. Kết quả này không có nhiều khác biệt so với các tác giả trong và ngoài nước khác $[1,7]$.

\subsection{Tỷ lệ tuân thủ tái khám}

Bảng 3. Tuân thủ tái khám của trẻ động kinh

\begin{tabular}{|c|c|c|}
\hline Tuân thủ tái khám & Số lượng & Tỷ lệ \% \\
\hline Tái khám đúng hẹn & 81 & 40,5 \\
\hline $\begin{array}{c}\text { Tái khám không } \\
\text { đúng hẹn }\end{array}$ & 114 & 57,0 \\
\hline Không tái khám & 5 & 2,5 \\
\hline
\end{tabular}

Tái khám thường xuyên cũng là yếu tố quan trọng ảnh hưởng tới tuân thủ điều trị. Việc tái khám thường xuyên giúp cho mối quan hệ bác sĩ - bệnh nhân chặt chẽ. Bác sĩ sẽ nắm rõ thông tin và giúp người bệnh nhận thức tốt hơn về tác dụng của uống thuốc đều đặn cũng như tác hại của việc bỏ điều trị. Qua nghiên cứu, chúng tôi thấy trong vòng 6 tháng có 40,5\% trẻ tái khám đúng hẹn, $57,0 \%$ trẻ tái khám không đúng hẹn và $2,5 \%$ không tái khám.

Lý do không tuân thủ tái khám đúng hẹn chủ yếu do người nuôi dưỡng bận việc hoặc trẻ bận học $(37,8 \%)$ và khoảng cách từ nhà tới bệnh viện xa $(26,1 \%)$. Các lý do khác như quên ngày tái khám $(20,2 \%)$, còn thuốc đang uống $(7,6 \%)$. Kết quả này cũng tương tự nghiên cứu của Trần Diệp Tuấn [1].

\subsection{Các yếu tố liên quan đến tuân thủ điều trị}

Bảng 4. Phân tích hồi quy đa biến các yếu tố liên quan đến tuân thủ điều trị

\begin{tabular}{|c|c|c|c|}
\hline Yếu tố & OR & $95 \% \mathrm{CI}$ & $\mathrm{p}$ \\
\hline $\begin{array}{c}\text { Nhóm tuổi 2-6 } \\
\text { tuổi }\end{array}$ & 2,12 & $1,06-4,34$ & $\begin{array}{c}0,0 \\
47\end{array}$ \\
\hline Có bảo hiểm y tế & 3,46 & $1,77-5,98$ & $\begin{array}{c}0,0 \\
02\end{array}$ \\
\hline $\begin{array}{c}\text { Tuổi khởi phát } \\
\text { cơn < 10 tuổi }\end{array}$ & 3,07 & $1,25-6,87$ & $\begin{array}{c}0,0 \\
29\end{array}$ \\
\hline $\begin{array}{c}\text { Thời gian điều trị } \\
\text { bệnh < 1 năm }\end{array}$ & 0,56 & $0,30-0,89$ & $\begin{array}{c}0,0 \\
38\end{array}$ \\
\hline $\begin{array}{c}\text { Tần suất cơn } \\
\text { (không có } \\
\text { cơn nào) }\end{array}$ & 0,48 & $0,21-0,76$ & $\begin{array}{c}0,0 \\
11\end{array}$ \\
\hline
\end{tabular}

Phân tích hồi quy logistic đa biến giữa các yếu tố liên quan đến tuân thủ điều trị khi kiểm soát các yếu tố còn lại cho thấy đều có ý nghĩa thống kê. Những bệnh nhân sử dụng dịch vụ có mức tuân thủ gấp 3,46 lần so với nhóm dùng bảo hiểm y tế. Có thể giải thích do người nuôi dưỡng trẻ chưa tin tưởng vào các loại thuốc chống động kinh trong diện bảo hiểm y tế, lo lắng về việc thuốc rẻ sẽ có nhiều tác dụng phụ. Những bệnh có cơn khởi phát trước 10 tuổi có mức tuân thủ gấp 3,07 
lần so với nhóm khởi phát cơn sau 10 tuổi. Chúng tôi cho rằng ở lứa tuổi này, bố mẹ lo lắng về việc gián đoạn học tập của con do đó quan tâm nhiều hơn đến việc cho trẻ đi khám định kỳ, tránh ảnh hưởng đến kết quả trên lớp. Những bệnh nhân điều trị $>1$ năm tuân thủ điều trị kém hơn $44 \%$ so với nhóm $<1$ năm. Và những bệnh nhân kiểm soát không tốt cơn động kinh có tỷ lệ tuân thủ kém hơn $52 \%$ so với nhóm kiểm soát tốt. Cả hai điều trên đều dễ giải thích do bệnh nhân thấy tiến triển của bệnh tốt hơn do đó tin tưởng vào quá trình điều trị, bởi lẽ đó mức độ tuân thủ cũng cao hơn.

\section{Kết luận}

43,5\% tuân thủ điều trị tốt, $40,5 \%$ tuân thủ tái khám theo hẹn. Các yếu tố liên quan có ý nghĩa thống kê với việc không tuân thủ điều trị thuốc ở trẻ em đó là: mức độ bảo hiểm y tế, tuổi khởi phát cơn, thời gian điều trị bệnh và tần suất cơn sau điều trị bệnh.

\section{Tài liệu tham khảo}

[1] Tuan TD. Assessment of treatment compliance and follow-up appointment for children with epilepsy at the Children's Hospital No.1. Journal of Medicine in Ho Chi Minh City 2016;20(1):172-179. (in Vietnamese)

[2] Ferrari CM, Cardoso de Sousa RM, Castro LH. Factors associated with treatment nonadherence in patients with epilepsy in Brazil. Seizure 2013;22(5):384-389. https://doi.org/10.1016/j.seizure.2013.02.006

[3] Cramer JA, Glassman M, Rienzi V. The relationship between poor medication compliance and seizures. Epilepsy Behav 2002;3(4):338-342. https://doi.org/10.1016 /s1525-5050(02)00037-9

[4] World Health Organization. Adherence to long-term therapies: evidence for action. Geneva; 2003, p. 81-87.

[5] Shope JT. Medication compliance. Pediatric Clinics of North America 1981;28:5-21.

[6] Deogratias M, Katabalo. Determinants of adherence to anticonvulsants and compliance health psychology - Processes and Applications. London, Chapman \& Hall; 2015, p. 74-102.

[7] Liu L, Yiu CH, Yen DJ et al. Medication education for patients with epilepsy in Taiwan. Seizure 2003;12(7):473-477. 